\title{
THE IMPACT OF GEOMETRY ERRORS ON THE MOTION TRANSMISSION OF DUAL PATH GEARING
}

\author{
Jacek Pacana' ${ }^{1}$ Andrzej Pacana ${ }^{1}$ \\ 1 Faculty of Mechanical Engineering and Aeronautics, Rzeszow University of Technology, Powstańców \\ Warszawy 8, 35-959 Rzeszów, Poland, e-mail: pacanaj@prz.edu.pl, app@prz.edu.pl
}

Received: 2016.07.14

Accepted: 2016.10.18

Published: 2016.12.01

\begin{abstract}
The article presents the numerical analysis of the impact of geometry errors on the motion transmission of dual path gearing. The strength calculations of the elements of the drive were made by means of the Finite Elements Method (FEM). The calculations were made for the two-dimensional models of the dual path gearing. In the first place, the drive of the error-free (theoretical) geometry was tested. Next, the modifications of the selected teeth were introduced to the calculation models. The aim of the modifications of the tooth profile was to simulate pitch errors in compliance with the admissible values defined by PN-ISO 1328-1:2015 norm "Cylindrical gears - ISO system of flank tolerance classification". Finally, all the results were put together for comparison. The obtained results confirm the high irregularity of work gear as a result of errors tooth geometry.
\end{abstract}

Keywords: gears, tooth pitch error, gears kinematics, motion transmission errors, FEM.

\section{INTRODUCTION}

Because the conducted analysis concerned the impact of geometry errors on the motion transmission of the dual path gearing, in the first place it was necessary to prepare an error-free model of theoretical geometry $[9,10]$. The model was prepared in $\mathrm{Au}-$ todesk Inventor software on the basis of the previous geometrical and strength calculations for the drive (Fig.1). Table 1 shows the main geometric parameters of the second stage of the dual path gearing.

The strength calculations for the error-free model were made with the use of the Finite Elements Methods in Abaqus software [1, 4, 6, 16]. The obtained results were used as a comparative basis for all subsequent models that were modified and tested.

The modifications of the tooth geometry were introduced to the analysed models with the aim to simulate pitch and centre distance errors $[2,11]$. The geometry errors were introduced on the ba- sis of the admissible values defined by PN-ISO 1328-1:2015-01E standard "Cylindrical gears ISO system of flank tolerance classification - Part

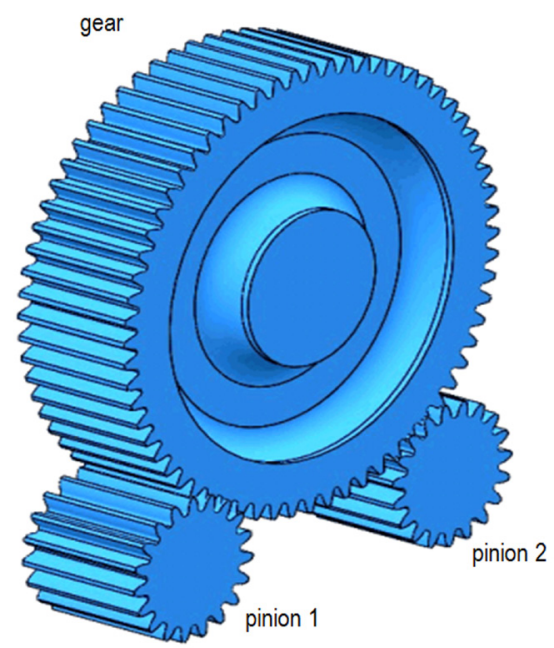

Fig. 1. The model of the second stage of the dual path gearing 
Table 1. Geometric parameters of the second stage of the dual path gearing

\begin{tabular}{|l|c|c|l|c|c|}
\hline \multicolumn{3}{|c|}{ Pinion 1, Pinion 2 } & \multicolumn{3}{c|}{ Gear Specification } \\
\hline Module [mm] & $\mathrm{m}$ & 2 & Module [mm] & $\mathrm{m}$ & 2 \\
\hline $\begin{array}{l}\text { Number of teeth } \\
{[\mathrm{mm}]}\end{array}$ & $\mathrm{z} 3$ & 19 & $\begin{array}{l}\text { Number of } \\
\text { teeth [mm] }\end{array}$ & $\mathrm{z} 4$ & 64 \\
\hline $\begin{array}{l}\text { Pitch diameter } \\
{[\mathrm{mm}]}\end{array}$ & $\mathrm{d} 3$ & 38 & $\begin{array}{l}\text { Pressure } \\
\left.\text { angle [ }{ }^{\circ}\right]\end{array}$ & $\alpha$ & 20 \\
\hline Teeth high [mm] & $\mathrm{h} 3$ & 4.5 & $\begin{array}{l}\text { Pitch diameter } \\
{[\mathrm{mm}]}\end{array}$ & $\mathrm{d} 4$ & 128 \\
\hline $\begin{array}{l}\text { Tooth face width } \\
{[\mathrm{mm}]}\end{array}$ & $\mathrm{b} 3$ & 30 & $\begin{array}{l}\text { Teeth high } \\
{[\mathrm{mm}]}\end{array}$ & $\mathrm{h} 4$ & 4.5 \\
\hline Profile angle [ $\left.{ }^{\circ}\right]$ & $\beta$ & $0\left[^{\circ}\right]$ & $\begin{array}{l}\text { Tooth face } \\
\text { width [mm] }\end{array}$ & $\mathrm{b} 4$ & 30 \\
\hline $\begin{array}{l}\text { Centre distance } \\
{[\mathrm{mm}]}\end{array}$ & $\mathrm{a}$ & 83 & $\begin{array}{l}\text { Profile angle } \\
{\left[{ }^{\circ}\right]}\end{array}$ & $\beta$ & $0\left[^{\circ}\right]$ \\
\hline
\end{tabular}

1: Definitions and allowable values of deviations relevant to flanks of gear teeth". At the end, all the results were put together for comparison and for drawing conclusions. The calculations were made for the two-dimensional models of the second stage of the dual path gearing (Fig. 2).

Because the spur gears (without the modification of the flank pitch line) were used in calculations, such simplification allowed to significantly save calculation time without affecting the accuracy of the calculations $[8,13]$.

A virtual model of the drive was taken as an initial model and it was limited to the samples necessary for the analysis of the engagement of several teeth. Such simplification does not affect the rigidity of the model and it saves a lot of time necessary for making calculations. It is particularly important as the calculations will be repeated many times during the task. The results of this analysis are very important because dual path gearing are often used in the aerospace in-

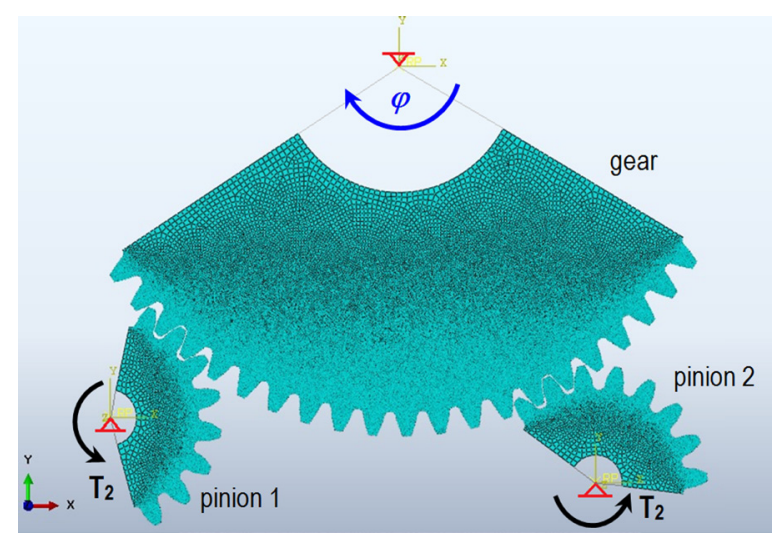

Fig. 2. The simplified model of the dual path gearing which underwent the process of discretisation

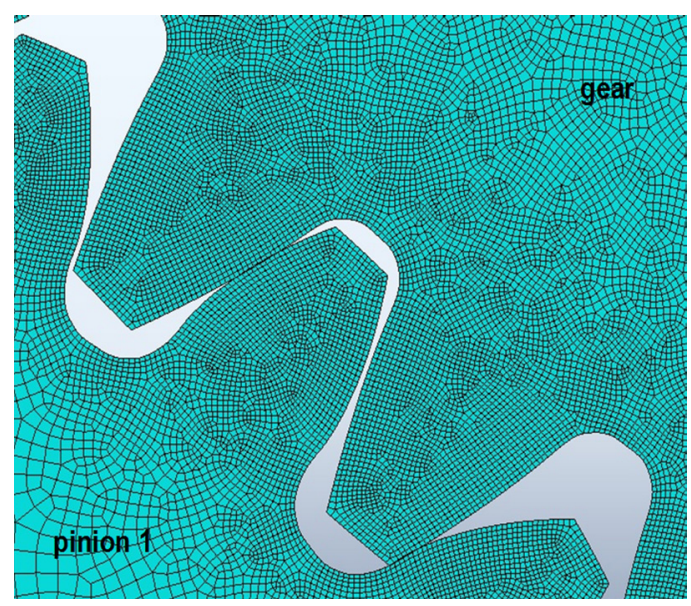

Fig. 3. Fragment of the model with the visible concentration of the finite elements mesh

dustry where their high reliability and durability are very needed.

\section{CALCULATION MODEL}

During the conducted analysis multiple calculations of one calculation model, with one specific parameter modified, were made. All other boundary conditions and the gear geometry remained the same in the next stages of calculations. Every pinion of the dual path gearing was loaded with the same torque moment $T_{2}=50 \mathrm{Nm}$. The position of the gear and the pinions was defined according to their actual character, by means of the constraints and the referent points (RP). All gear models of the analysed drive underwent the process of discretisation with the use of linear quadrangular elements. Heavy concentration of the finite elements mesh, in the areas of the gear toothed rings, is visible due to the predicted occurrence of the highest stress values in those areas (Fig. 3).

The rotation of the gear, by the angle $\varphi=0.5$ radians, was set in the axle of the gear in order to simulate the actual engagement of several teeth of both gears of the drive. What is more, the calculations were divided into 100 steps with the rotation by the angle of 0.005 radians in each step.

Thanks to that, it was possible to precisely analyse the engagement on the entire fragment of tooth contact. The actual calculations were made in the solver of Abaqus software after the preparation of the models. The results of the calculations were saved in the adequate output files, separately for each analysed type of the drive. 


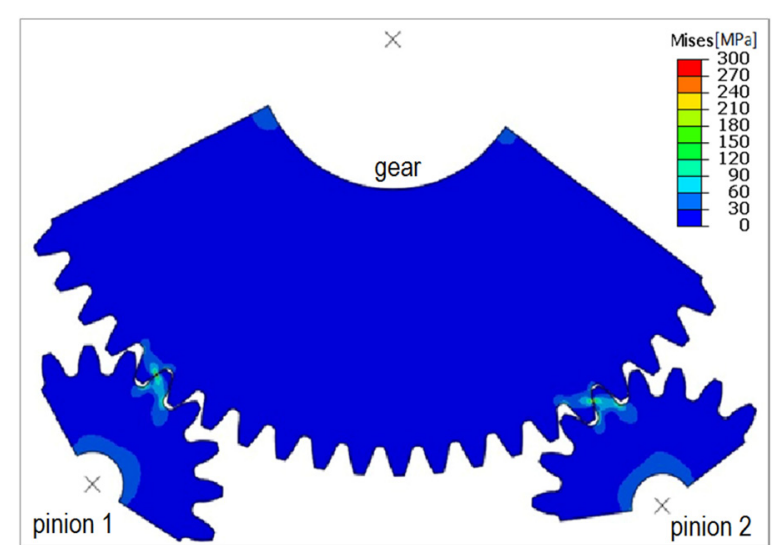

Fig. 4. Reduced stress distribution for the model of the dual path gearing

\section{THE ANALYSIS OF THE SOLUTIONS}

As a result of the conducted calculations the correct solutions for all calculation variants were found. Figure 4 presents the results for the initial model of the second stage of the dual path gearing.

The results in this form are not legible enough so they cannot be used for comparative analysis.

\section{The bending stresses}

That's why, the graphs of bending stress at the tooth root for the pinion models and the gear were presented. In both areas the maximum stress values (marked as "A" on the Figure 5) were obtained in the next 100 calculation steps.

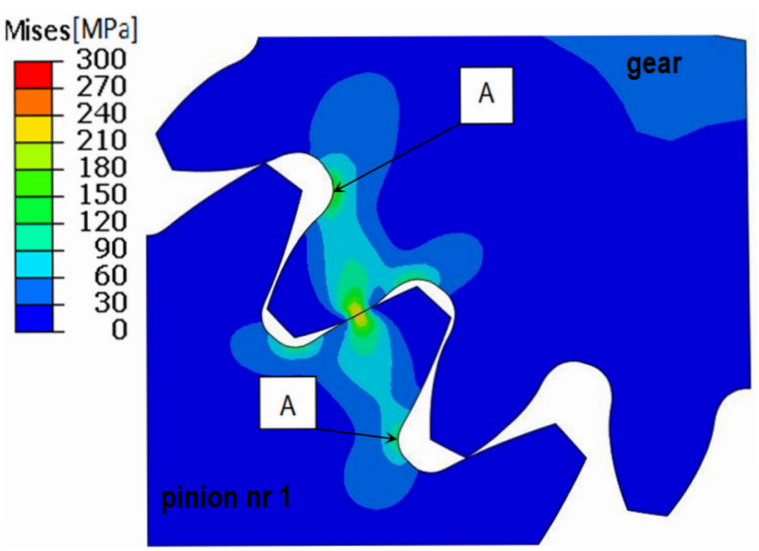

Fig. 5. Reduced stress distribution presented for the area of mating of the gear with pinion nol

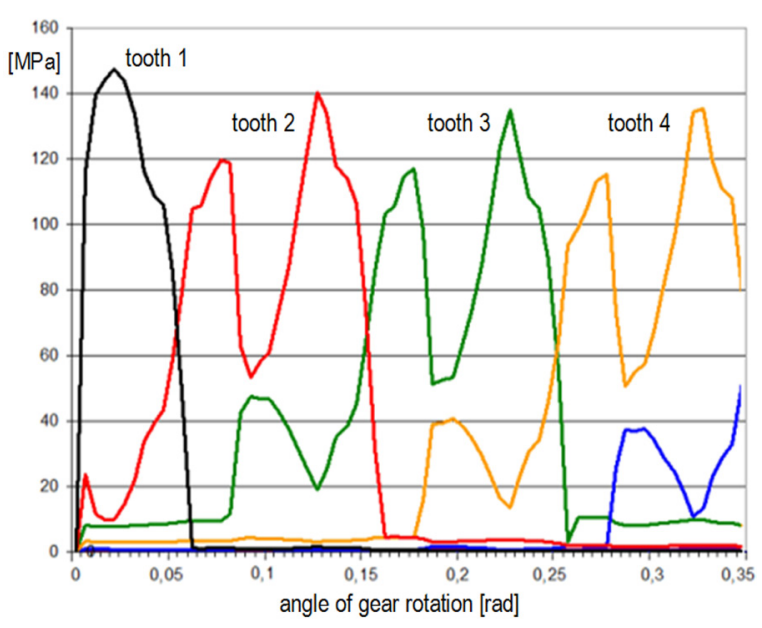

Fig. 6. Graph of bending stress at the tooth root for pinion no 1 , for the model of the second stage of the dual path gearing

Thanks to that, the character of the changes of the load, for the several pinion and gear teeth, was precisely analysed.

Because the parallel mating of both pinions with the gear was assumed, the graphs for each of them are similar. In the next steps of the analysis the focus was on the contact between pinion no 1 and the gear and it was observed that all graphs for pinion no 2 had a similar shape. Figure 6 presents the graph of bending stress at the tooth root for pinion no 1 , for the initial model of the second stage of the dual path gearing. Figure 7 presents the same graph for the gear mating with the pinion no 1 .

We can notice that the shape of the graph is not smooth and there are clearly visible high stress concentrations in the moment when teeth

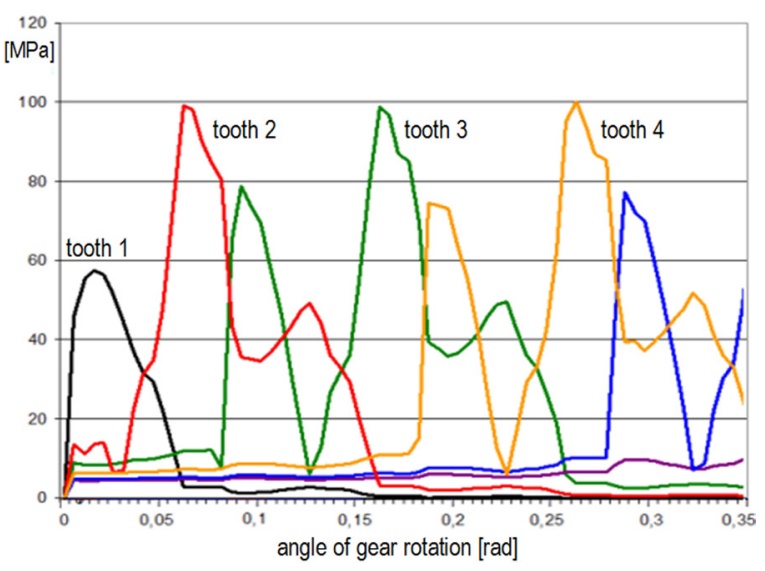

Fig. 7. Graph of bending stress at the tooth root for the gear, for the model of the second stage of the dual path gearing 
enter and exit the area of engagement. However, the course of stress changes is repetitive for the subsequent teeth, which guarantees smooth operation of the drive. Such character of the graph is known in literature and it is characteristic for spur gears.

After obtaining the results presented above, the shape of the teeth was modified by introducing the changes into the geometry. However, in all cases the error values were within the acceptable range of the adequate standards.

In the first stage of the calculations, for one pinion tooth engaged with one gear tooth, the pitch error of $5 \mu \mathrm{m}$ value (in favour) was introduced in such a way that the errors totalled. This value was assumed as a maximum admissible value of the pitch error in accordance with the PN-ISO 1328-1:2000 standard. The graphs of bending stress at the tooth root, for the successive pinion teeth engaged with the gear teeth, were presented in Figure 8.

The graphs obtained on the basis of the modified geometrical models are no longer similar to the initial graphs. The shape of the graph of bending stress at the tooth root changed significantly for the modified tooth of gear. The time of engagement between those teeth is considerably longer than between all other teeth and the stress values are considerably higher than in the initial variant of the gear model.

\section{The motion graphs}

On the basis of the same numerical calculations, with the use of the functions available in the post-processor of Abaqus software, we can also create motion graphs for the [14]. Such graphs allow to determine rotational speed of the gear, its acceleration as well as the errors, i.e. deviations from the constant value of the theoretical speed assumed for the calculations. The construction of the gear suggests that the rotational speed of the gear is not constant as, in the moment when teeth enter and exit the area of engagement, there are momentary speed changes which result from the necessary clearance in the construction. The legible picture of that is presented in the motion graph for the non-modified gear (Fig. 9).

The graph presents the angular difference $(\Delta \varphi)$ between the calculated value, that results from the gear ratio, and the actual rotation of the gear, that mates with pinion no 1 . All positive values correspond to the accelerations and their momentary high concentrations, in the moment of the initiation of tooth engagement, are particularly visible. We can see that the engagement runs smooth and is periodical and the momentary accelerations have the same values for all subsequent teeth. When we compare the shape of the motion graph with the shape of the graph of bending stress at the tooth root, we can draw the conclusion that they are closely linked. Values that correspond to the smaller than assumed rotational speed of the gear are below the axis. The acute (not smooth) character of the graph results from the use of the discrete gear model, however, it does not affect the legibility of the main trends in the shape of the graph.

The introduced modification is reflected in the motion transmission of the gear. Figure 10 presents the graph (prepared for the gear) with the assumed maximum positive pitch error for

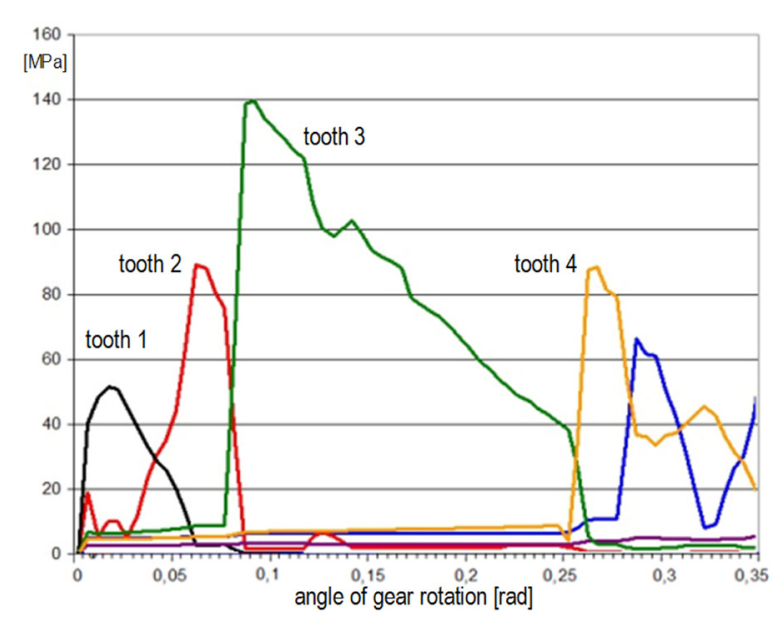

Fig. 8. Graph of bending stress at the tooth root for the gear, for the maximum positive pitch error

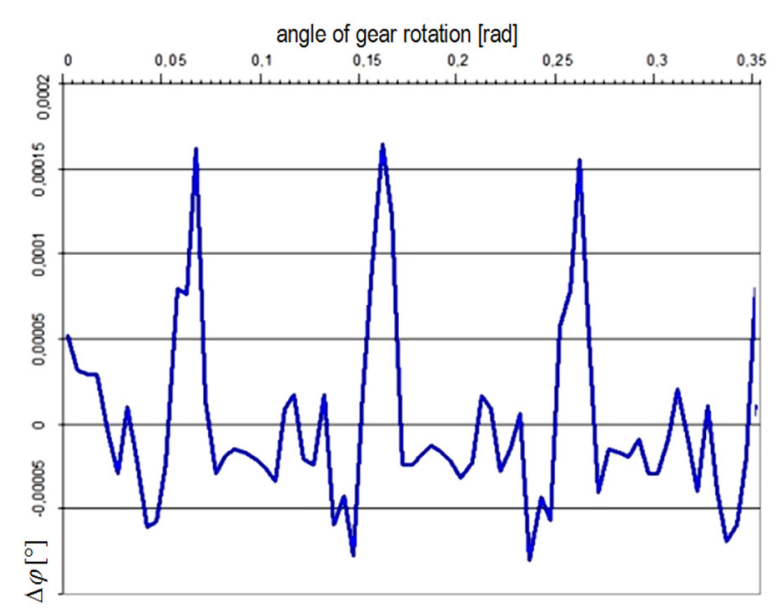

Fig. 9. Motion graph for the gear in its initial variant 


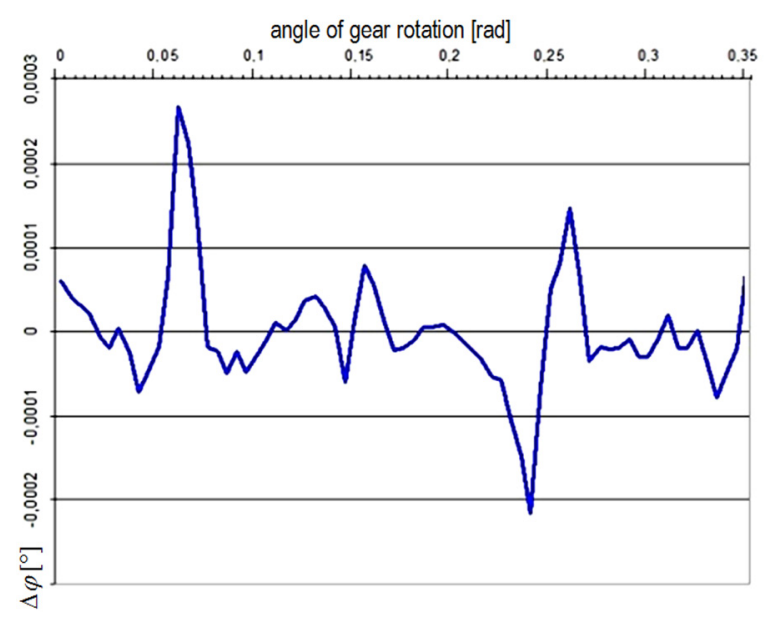

Fig. 10. Motion graph for the maximum positive pitch error

one tooth. For the fragment of the graph presenting the modified tooth, the shape is smoother. The introduction of the pitch error (in favour) resulted in the earlier entrance and later exit from the area of tooth engagement than in the case of the errorfree geometry (Fig. 9). This, however, caused much higher error values of rotational angle of the gear than in the case of the error-free gear.

Another analysed solution is a model in which the maximum value of the pitch error for the gear tooth engaged with the pinion tooth was again introduced. This time, however, the pitch error was introduced into the inside of the material. The motion graph of the gear was presented in Figure 11.

In this case, the engagement of the modified tooth is considerably shorter than in the

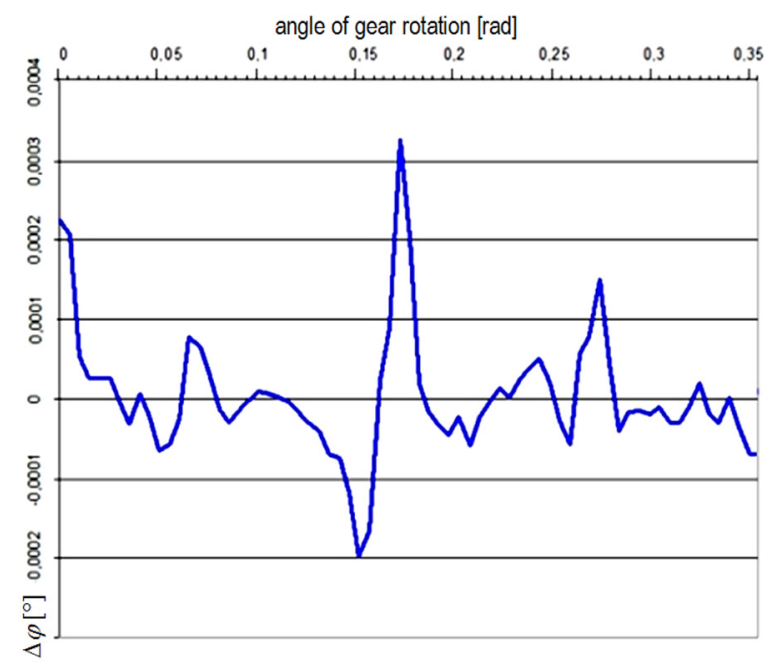

Fig. 11. The motion graph for the gear with the maximum negative pitch error

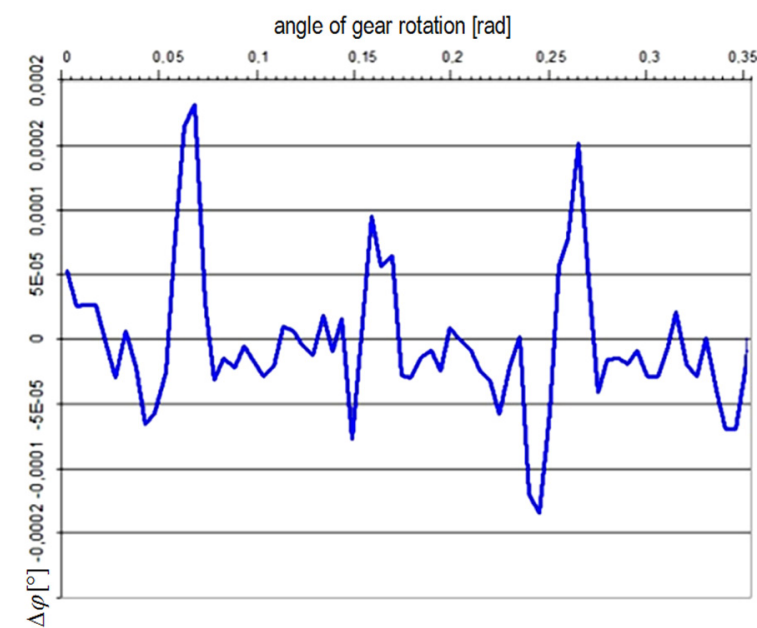

Fig. 12. Motion graph for the assumed positive pitch error for the one pinion tooth only of pinion into the value $5 \mu \mathrm{m}$ inside of the material - the gear was assumed as a initial variant, i.e. as error-free model

case of the remaining standard-made teeth. For this tooth the value of difference between the nominal and actual rotational angle of the gear is twice as high as in the case of the remaining teeth. The time of engagement of that tooth is considerably shorter, whereas the time the engagement of the neighbouring teeth is longer. It is a very unfavourable situation as, apart from the distraction in motion transmission and louder operation, it also causes considerable increase in the stress values.

The third variant of the geometry modification concerned the situation in which the gear was assumed to be manufactured accurately and the pitch error of $5 \mu \mathrm{m}$ value (on the outside) was introduced to one pinion tooth only. In the case of this calculation model the motion graph was also created (Fig. 12). The presented graph cannot be assumed as satisfactory, however, this situation seems to be the most favourable of all modified variants. The graph is smoother and the maximum error values of the rotational angle are the lowest of all modified variants.

In this case, the increase in the error values of the rotational angle for the modified tooth is also clearly visible (Fig. 13).

The difference of the values between the modified and nominal teeth may not be significant, but it causes uneven distribution of the load, which may affect gear durability.

The last of the analyzed calculation case is similar to the previous one. However, this time the pitch errors was introduced on the one tooth. 
Figures $10-13$ present the motion graphs for the dual path gearing. The initial variant for the theoretical drive is the most regular. Sudden increase in the values is related to the moment in which the engagement between subsequent teeth starts, which indicates sudden acceleration of the gear rotation during that time. The subsequent graphs for the models with the introduced pitch error no longer have such a repetitive shape which occurs periodically. In all cases the differences occur in the area of the third tooth (the one that was modified) and in some cases they cause considerable errors in the rotational angles of the gear.

\section{CONCLUSIONS}

The conducted numerical analysis focused on determining the impact of the geometry errors on the load distribution in the dual path gearing. The calculations were made with the use of two-dimensional models. This made the preparation of the models easy, the time of calculations shorter and the processing of the obtained results easy. The calculations, with the use of FEM, were made in Abaqus 6.11 software.

The error-free drive was selected as an initial version. In the next steps of the calculations the pitch errors were introduced. The solutions, obtained for the subsequent versions, were compared with the initial variant, which led to the conclusion that there were differences not only in stress values but also in the character of the gear operation, which results from the geometry errors. The observed additional distractions in motion transmission will result in much louder gear operation and vibrations, which will affect the durability of the entire dual path gearing $[5,7,15]$.

The prepared motion graphs for the pinion, for all analysed versions of the pitch error, help to approach the problem adequately $[3,12]$. Careful analysis, which will allow to discover and define the unfavourable phenomena, will lead to the right solutions. The adequate transfer of the load in the multi-path gearing may improve both - the quality of operation as well as the durability of gears used in aviation.

It is necessary to be extremely careful when manufacturing gears of the most accurate profile possible, as it may significantly prolong its durability.

\section{REFERENCES}

1. Ambarisha V. K. and Parker R.G. Nonlinear dynamics of planetary gears using analytical and finite element models. Journal of Sound and Vibration, 302(3), 2007, 577-595.

2. Bonori G., Barbieri M. and Pellicano F. Optimum profile modifications of spur gears by means of genetic algorithms. Journal of Sound and Vibration, 313(3-5), 2008, 603-616.

3. Bouzakis K.-D., Lili E., Michailidis N. and Friderikos O. Manufacturing of cylindrical gears by generating cutting processes: A critical synthesis of analysis methods. CIRP Annals - Manufacturing Technology, 57(2), 2008, 676-696.

4. Budzik G., Kozik B. and Pacana J. Defining influence of load conditions on distribution and value of stresses in dual-power-path gear wheels applying FEM. Aircraft Engineering and Aerospace Technology, International Journal, 85(6), 2013, 453-459.

5. Budzik G. and Pacana J. Analiza poprawności rozwiązania MES w zależności od rodzaju oraz liczby zastosowanych elementów skończonych. Acta Mechanica Slovaca, Kosiče 2008, 3-A/2008.

6. Chen Z. and Shao Y. Mesh stiffness calculation of a spur gear pair with tooth profile modification and tooth root crack. Mechanism and Machine Theory, 62, 2013, 63-74.

7. Dziubek T. The determination of accuracy of testing gear wheel for aeronautical dual-power path gear after heat treatment. Diagnostyka, 15(2), 2015, 61-65.

8. Fernandez del Rincon A., Viadero F., Iglesias M., García P., de-Juan A. and Sancibrian R. A model for the study of meshing stiffness in spur gear transmissions. Mechanism and Machine Theory, 61, 2013, 30-58.

9. Inalpolata M., Handschuhb M. and Kahramanb A. Influence of indexing errors on dynamic response of spur gear pairs. Mechanical Systems and Signal Processing, 60-61, 2015, 391-405.

10. Jiang J. and Fang Z. Design and analysis of modified cylindrical gears with a higher-order transmission error. Mechanism and Machine Theory, 88, 2015, 141-152.

11. Kozik B. and Sobolak M. Increasing uniformity of power distribution in dual-path gear transmission. Diagnostyka, 16(3), 2015, 65-68.

12. Li S. Effects of misalignment error, tooth modifications and transmitted torque on tooth engagements of a pair of spur gears. Mechanism and Machine Theory, 83, 2015, 125-136.

13. Li S. Finite element analyses for contact strength and bending strength of a pair of spur gears with 
machining errors, assembly errors and tooth modifications. Mechanism and Machine Theory, 42(1), 2007, 88-114.

14. Płocica M. and Pisula J. The influence of changes in the geometry of the tooth surface of the pinion bevel gear on the kinematic accuracy of pair mesh. Acta Mechanica et Automatica, 8(2), 2014, 95-98.
15. Wilk A., Madej H. and Figlus T. Analysis of the possibility to reduce vibroactivity of the gearbox housing. Eksploatacja i Niezawodnosc - Maintenance and Reliability, 2, 2011, 42-49.

16. Wang Y., Zuo M. J., Lei Y. and Fan X. Improvement of local mean approximation in empirical mode decomposition for gear fault detection. Eksploatacja i Niezawodnosc - Maintenance and Reliability, 2, 2010, 59-66. 